\title{
Ultrasonographic assessment of male anterior urethra. Description of the technique of examination and presentation of major pathologies.
}

\author{
Jakub Krukowski, Mikołaj Frankiewicz, Adam Kałużny, Marcin Matuszewski
}

Department of Urology, Medical University of Gdańsk, Gdańsk, Poland

\begin{abstract}
During the last years the role of sonourethrography (SUG) in the assessment of anterior male urethra pathologies, has significantly increased. The investigation is easily performed, not time consuming and should be considered the imaging technique of choice for preliminary diagnosis, without exposing the patient to X-rays. In this paper we present the technique of examination and the most common pathologies in which SUG is indicated.
\end{abstract}

Keywords: male anterior urethra; sonourethrography; ultrasonography; urethral disease

\section{Introduction}

For almost a hundred years, retrograde and voiding cystouretrography (R-CUG and V-CUG) have been the basic examination used in the imaging of the male urethra [1]. This test involves the urethra assessment using $\mathrm{X}$-rays, after having previously filled it with contrast. This currently used technique was described in the 1960s and still is used as the "gold standard" in the diagnosis of urethral disorders [2]. Despite many advantages, which are, among others, ease of execution and the ability to assess the entire urethra from the meatus to the bladder, this examination is not an ideal tool in the urethral pathology diagnosis. The lack of evaluation of the urethra in three dimensions, radiation or administration of a potentially sensitizing contrast agent are among the major disadvantages that prevent CUG from being awarded the title of an "ideal test".

Received 25.01.2020 Accepted 16.03.2020

Med Ultrason

2020, Vol. 22, No 2, 236-242

Corresponding author: Jakub Krukowski, MD

Department of Urology, Medical University of Gdańsk, Gdańsk, Poland

Smoluchowskiego 17 St., 80-952, Gdańsk, Poland

E-mail: jakub.i.krukowski@gmail.com
The next step in the development of urethral imaging techniques was the introduction of sonouretrography (SUG). The "milestone" was the presentation of the first results of the use of ultrasonography in the urethral strictures' diagnosis by McAninch et al [3]. This study began the development of SUG as a diagnostic tool for urethral damage.

Over the past 30 years, numerous papers have appeared describing the role and usefulness of ultrasound examination of the urethra. The purpose of this article is to introduce the study technique itself and to describe the most common pathologies that can be encountered during examination.

\section{Technique of examination}

The technique of examination has not changed since its first description [3]. After decontaminating the meatus, a Foley catheter is inserted into distal segment of the urethra. To stabilize the catheter, at the level of fossa navicularis, the catheter's balloon is filled to a volume of up to $2 \mathrm{~mL}$ (or the appearance of discomfort). An alternative to the catheter is the use of a penis clamp dedicated to this study [4]. In patients with meatal stenosis, when the catheter cannot be inserted into the urethra, a peripheral venous catheter can be used instead of the Foley catheter to deliver fluid into the urethra (fig 1) [5]. 


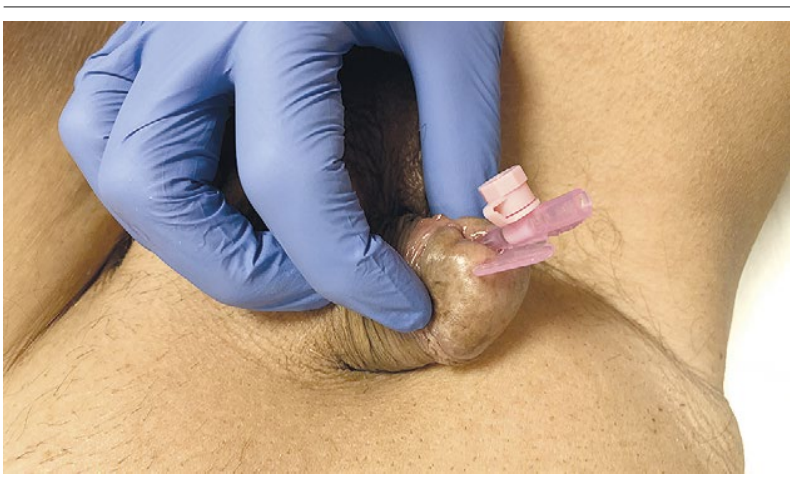

Fig 1. Technique of insertion of fluid to the urethra in a patient with meatal stenosis: installation of peripheral venous catheter to the urethra.

There are two techniques for delivering fluid to the urethra. In the most widely used, $20-100 \mathrm{~mL}$ of fluid, mainly $0.9 \%$ solution of Natrium Chloratum $(\mathrm{NaCl})$, is injected with a syringe through the catheter [3]. In the second, a vial of fluid is placed up to $200 \mathrm{~cm}$ above the patient, to get the right fluid pressure and thus proper urethral extension [4]. Healthy urethra is presented as a uniform, echo-free area, surrounded by the corpus spongiosum, with a diameter between 8 to $10 \mathrm{~mm}$ (fig 2). Below the urethra an echogenic band can be presented produced by dorsal acoustic enhancement and reflection from the tunica albuginea.

Because of the risk of generating artifacts (air bubbles) during installation and the weak extension of urethra, the use of gel is not recommended (fig 3).

Patients with a completely closed urethra are challenging for the examiner. In these cases, examination preparation is divided into two steps. During the first part, through the suprapubic catheter, the bladder is filled up to $300-400 \mathrm{ml}$ (or to the first strong sensation of micturition). In the second step, in the distal part of the penile urethra the Foley catheter is installed. After the filling of

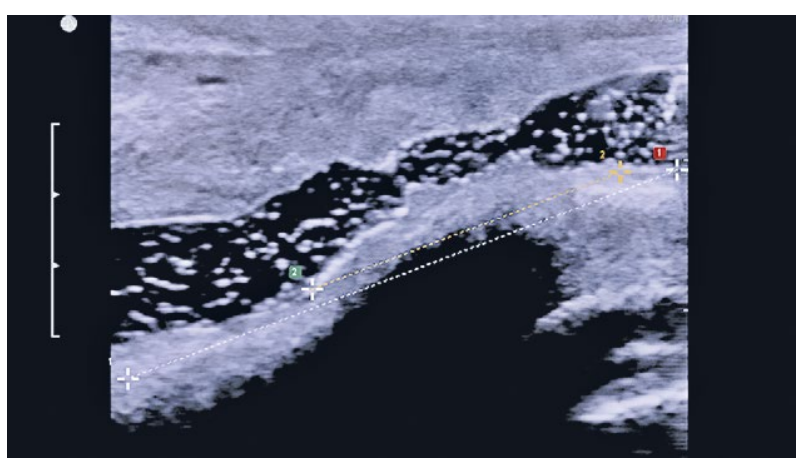

Fig 3. Urethral stricture (borders marked by pointers). In the urethral lumen the "snow storm" effect is visible after the use of gel to the extension of the urethra

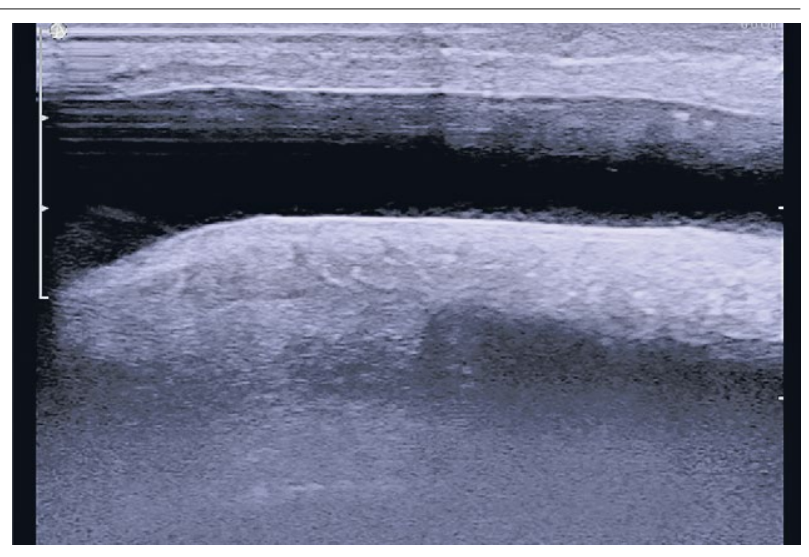

Fig 2. Healthy male anterior urethra

the distal urethra, the patient is asked to push on the bladder. During this manoeuvre the bladder neck opens and the urethra proximal to the stricture is stretched by the fluid (fig 4).

To facilitate the study, after positioning the penis on the midline of the hypogastric region, it can be immobilised by a strip of surgical tape. To assess the distal part of penile urethra (especially fossa navicularis and meatus), the examination can be performed during the voiding phase. This allows for the appropriate stretching of the urethra and thus enables a better assessment of possible pathologies within this part of the urethra.

The linear probe is the tool of choice. The transducer is placed lengthways on the ventral region of the penis and then moved transscrotally and transperineally to visualize the bulbar urethra. Due to the short distance between the urethra and the skin, the highest possible frequencies should be used to obtain the most accurate image. No strict rules are used concerning the frequencies Briefly, they depend on which urethral segment is

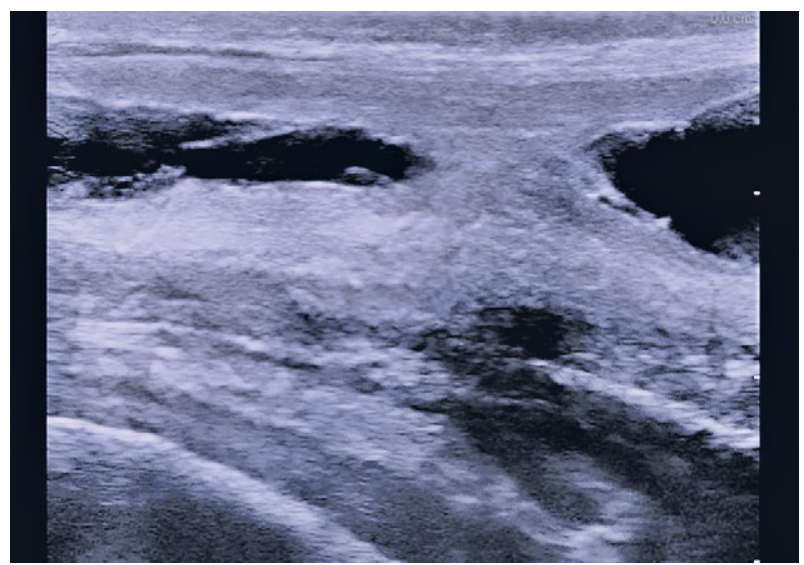

Fig 4. Urethral stricture. The scar completely closed the urethral lumen. 


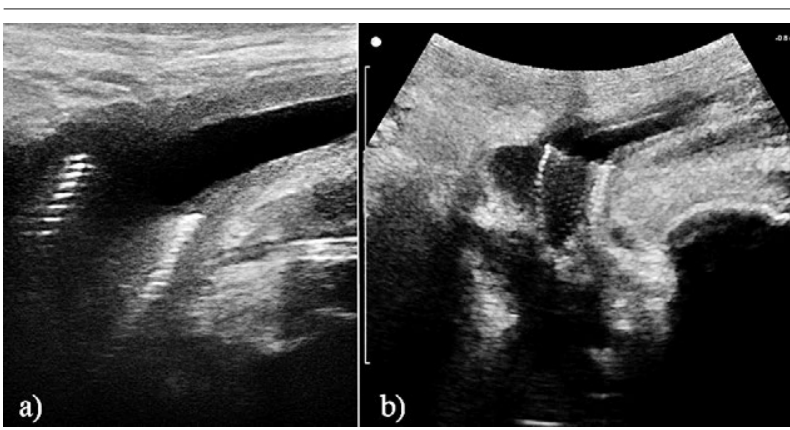

Fig 5. Assessment of the junction of the bulbar and membra-

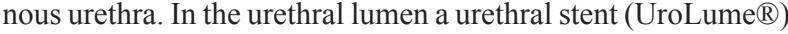
is visible. ( $5 \mathrm{a}-$ linear probe, $5 \mathrm{~b}-$ convex probe).

examined and on the thickness of the fat tissue around the perineum. In some cases, especially to assess a junction between the bulbar and the membranous urethra, a better option is using a convex probe (fig 5). In our opinion the best frequencies are $15-18 \mathrm{MHz}$ for the penile urethra (from meatus to the peno-scrotal angle) and 9-12 MHz for the bulbar urethra (up to the urethral external sphincter). To avoid generating artefacts, especially false views of the stricture, the pressure of the probe on the urethra cannot be too high.

\section{Urethral stricture}

The main cause of the urethral stricture is the formation of a concentric scar within the corpus spongiosum, as result of inflammation caused by injury or infection. This creates a stiff, non-stretchable section of the urethra.

In the SUG, the damage is visible as a part of urethra that does not stretch during the filling of the urethra by fluid (fig 6). Assessment of the length of urethral scarring is performed by measuring a hyperechogenic line on the urethral mucosa. Depth of fibrotic corpus spongiosum can be measured by the assessment of the hyperechogenic part of this tissue.

In comparison to CUG, SUG has a higher accuracy in determining a length of urethral stricture. The correlation coefficient between the length of stricture measured during SUG and operation is between 0.73 and 0.92 , and the highest accuracy is presented for penile urethra $[6,7]$. Sonoelastography, in comparison to the grey-scale ultrasound technique, improves the accuracy of the spongiofibrosis assessment [8].

There are two classifications assessing the degree of urethral damage. The first is the three-stage scale proposed by McAninch et al [3]. It estimates the degree of narrowing of the urethral lumen at its narrowest point. The scale indirectly determinates the degree of fibrosis of corpus spongiosum (Table I.). In comparison to histopathological findings, the accuracy of this scale in the assessment of spongiofibrosis is about $56 \%$ [9]. The sec-

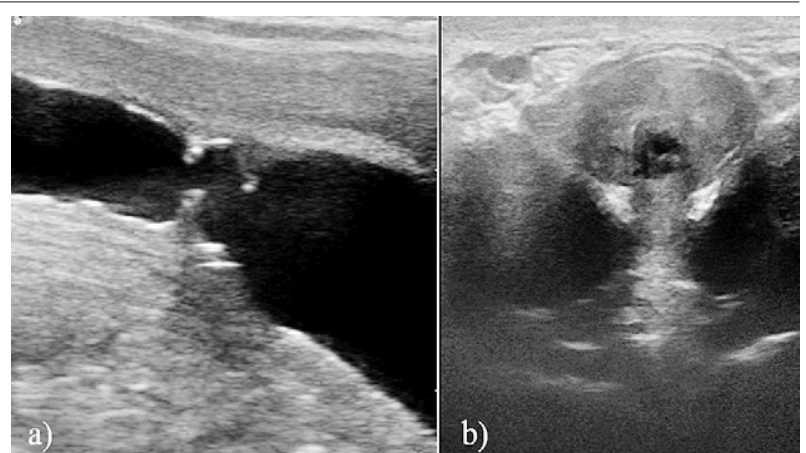

Fig 6. Stricture in the bulbar part of urethra: 6a) longitudinal view; 6b) transverse view.

ond classification is the five-level grading proposed by Chiou et al [10]. In this case, the staging of the urethral stricture depends on the number and length of the stricture and the amount of spongiosal tissue involvement (Table II.).

\section{Urethral diverticulum}

Urethral diverticulum is a condition where the urethra or the periurethral glands push into the spongiosal tissue that surrounds it. The lesion usually occurs at the penoscrotal junction or the bulbous urethra [11]. Up to $10 \%$ of patients with urethral diverticulum develop stone formation [12]. Acquired urethral diverticula can be a result of stricture, infection or trauma. But the most common cause is the surgical treatment of urethral strictures [13]; especially substitution urethroplasty with oral mucosa graft. In this situation the diverticulum may have a considerable size [14].

Table I. McAninch et al [3] classification of the urethral stricture.

\begin{tabular}{ll}
\hline $\begin{array}{l}\text { Urethral stricture } \\
\text { staging }\end{array}$ & $\begin{array}{l}\text { Degree of lumen occluded } \\
\text { based on SUG }\end{array}$ \\
\hline Mild & $<1 / 3$ \\
Moderate & $1 / 3-1 / 2$ \\
Severe & $>1 / 2$ \\
\hline
\end{tabular}

SUG, sonourethrography

Table II. Chiou et al [10] classification of the urethral stricture.

\begin{tabular}{|c|c|}
\hline Stricture grading & Ultrasonographic finding \\
\hline $\mathrm{I}$ & $\begin{array}{l}\text { Short stricture with minimal } \\
\text { spongiosal tissue involvement }\end{array}$ \\
\hline II & $\begin{array}{l}\text { Short stricture with moderate } \\
\text { spongiosal tissue involvement }\end{array}$ \\
\hline III & $\begin{array}{l}\text { Short stricture with extensive } \\
\text { spongiosal tissue involvement }\end{array}$ \\
\hline IV & $\begin{array}{l}\text { Long or multiple strictures with } \\
\text { moderate spongiosal involvement }\end{array}$ \\
\hline V & $\begin{array}{l}\text { Long or multiple strictures with } \\
\text { extensive spongiosal involvement }\end{array}$ \\
\hline
\end{tabular}




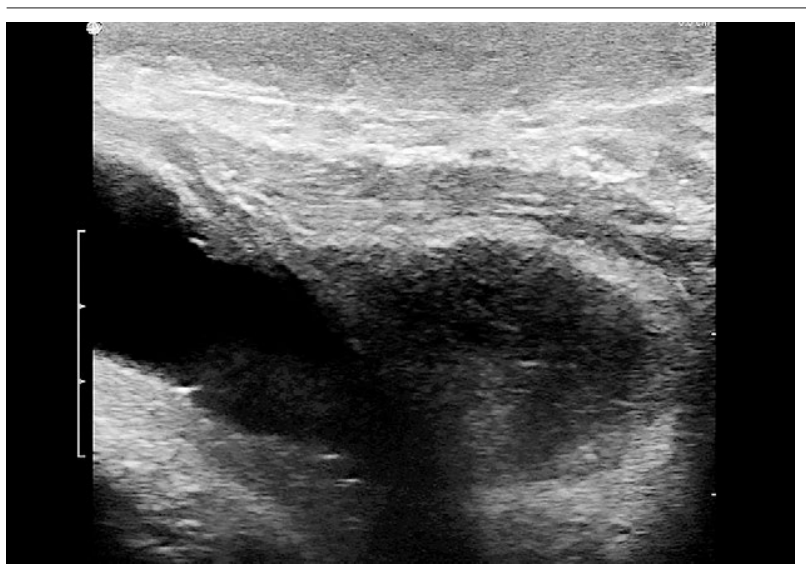

Fig 7. Urethral diverticulum. Diverticulum developed in the place previously operated because of the urethral stricture (augmented by buccal mucosal graft).

US can demonstrate a relatively echo-free cavity adjacent to the urethra. The communication between the urethral diverticula and true urethral lumen may have a narrow or a wide neck (fig 7).

SUG presents $100 \%$ sensitivity and $98 \%$ specificity in the diagnosis of urethral diverticula [15].

\section{False passage}

False passage is usually presented in patients after traumatic catheterisation or a previous urethral operation. Typically, it is localised in the urethral angle. In most cases the false passage goes back toward the posterior urethra. In this situation, during voiding, the urinary stream closes the mucosal flap. This fact results in most cases, that the false passage is invisible during V-CUG [16].

The anatomical variant that can be misdiagnosed as a false passage is a duplication of the urethra. Types of this accessory organ may vary from a blind closed channel to a completely developed second urethra [17].

Sensitivity and specificity for SUG and R-CUG in the diagnosis of false tract is $100 \%$ [15].

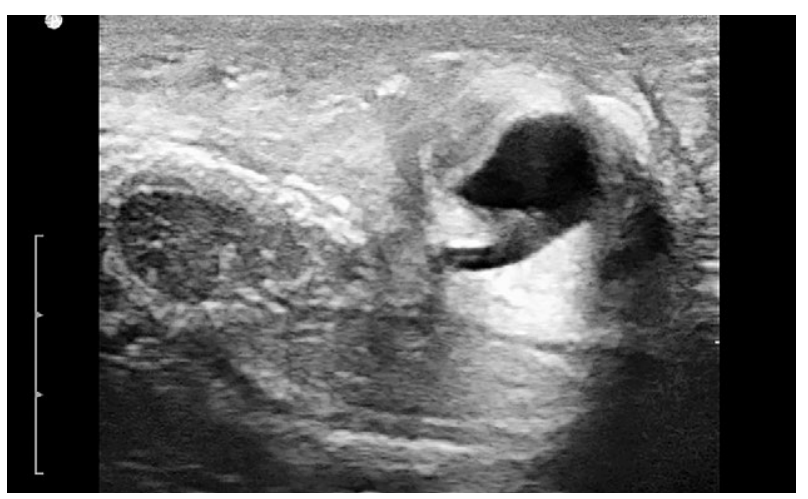

Fig 9. Urethral fistula in a patient with a urethral stricture (transverse view of the bulbar part of urethra).

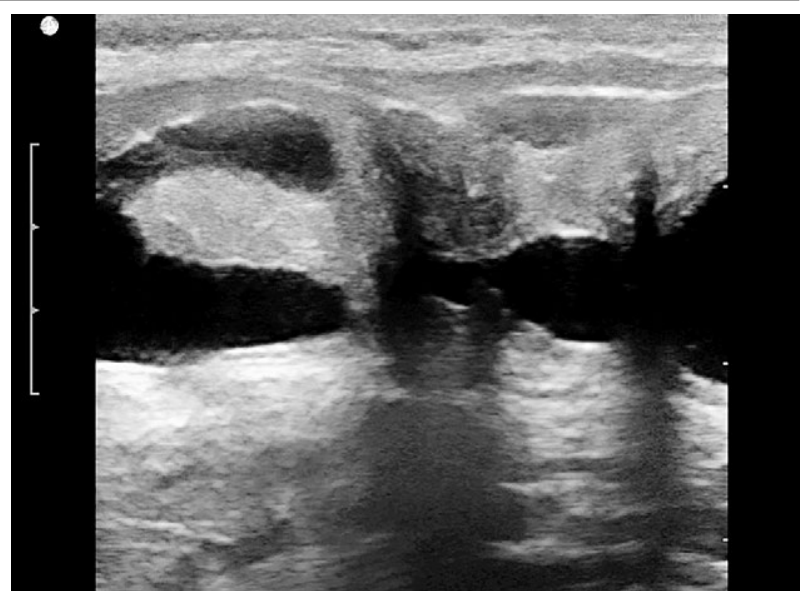

Fig 8. Urethral stricture. False passage in the penile part of urethra.

In SUG, during retrograde fluid insertion, false passage is presented as a channel running along the true urethral lumen (fig 8). The border between the channels is urethral mucosa. Careful evaluation of periurethral structures and proper transverse scanning is needed.

\section{Urethral fistulas}

Urethroperineal fistulas and urethrocutaneous fistulas may result from surgical treatment of urethral strictures, repair of hypospadias, prostate surgery, chronic untreated periurethral abscesses and trauma [18].

In US a fistula is visible as an echo-free canal that goes from the urethral lumen, through the corpus spongiosum, to the skin (fig 9). In comparison to CUG, SUG can easier identify an origin of fistula and delineate the periurethral extent [10].

\section{Urethral calculi}

Most urethral calculi consist of small stones expelled from the bladder into the urethra during voiding; these are referred to as migrant calculi. Occasionally, however, a stone may be large enough to become lodged at a point

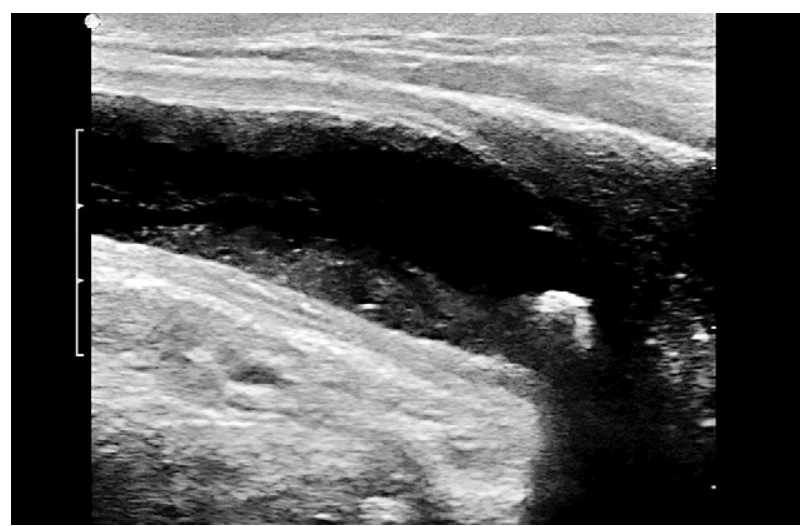

Fig 10. Urethral calculus in the bulbar urethra. 


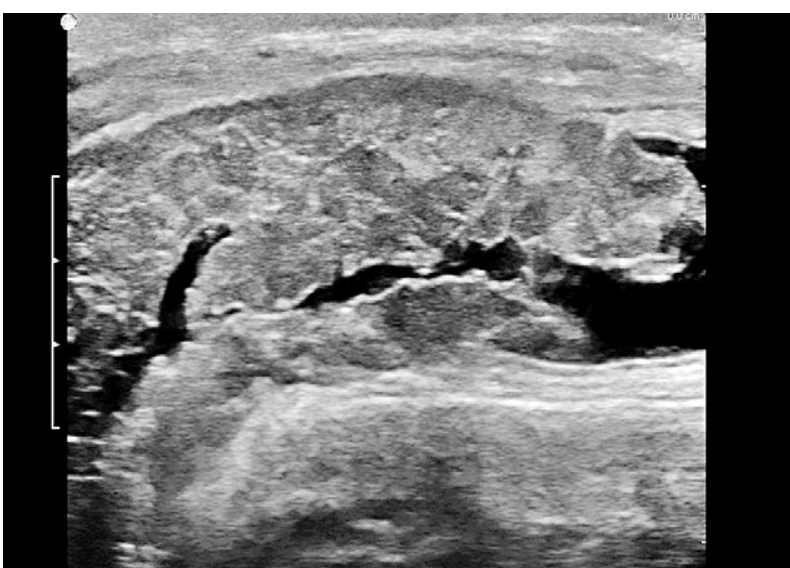

Fig 11. Primary urethral cancer.

of urethral narrowing such as the membranous urethra. Rarely, primary (native) formation of a stone occurs in the urethra when the stricture is present, or it may be associated with a urethral diverticulum $[19,20]$.

In USG, the picture of calculus is similar to stones in other parts of the urinary tract. It is presented as a hyperechogenic structure with acoustic shadowing, sometimes mobile, localised in the urethral lumen (fig 10). In colour Doppler the "twinkling artifact" can be presented. One of the main problems during SUG are the air bubbles developed during fluid intake. Because they can look like small stones, they may be accidentally taken for calculi.

\section{Condyloma acuminata}

Genital warts are skin papules that are formed as a result of epidermal hyperplasia. They belong to a group of conditions resulting from Human Papillomavirus (HPV) infection. Urethral involvement affects $0.5-5 \%$ of cases. Due to the risk of spreading the virus, retrograde fluid administration is not recommended. Voiding SUG becomes the test of choice. In the ultrasound image, 3 forms of lesions corresponding to condyloma can be distinguished: polyp, papilloma and, the most common, cauliflower mass [21].

\section{Primary urethral cancer}

Primary urethral cancer is one of the rarest cancers of the urinary tract. Bulbar urethra is the part most commonly affected by the tumor, followed by the penile and prostatic urethra. Due to non-specific symptoms, this cancer is most often detected at the locally advanced stage.

SUG is not the imaging tool of choice, thus not much information about ultrasonographic morphology of this tumor is provided in the literature. The appearance of a tumor closely depends on the stage. Less advanced cancer resembles a polypous structure on the urethral mucosa. In more advanced stages, urethral cancer is seen as a well-delimited, heterogeneous, well vascularized, ir-

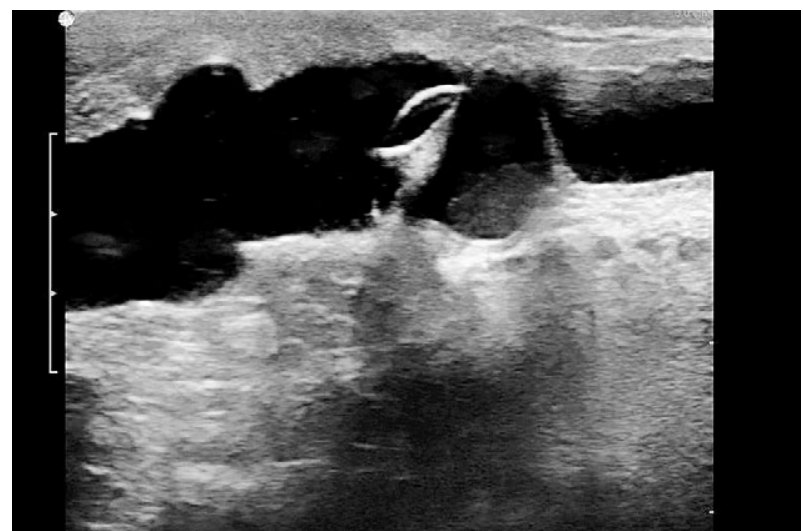

Fig 12. Neourethra in a patient after female-to-male conversion. Hairs in the urethral lumen.

regular structure closing of the urethral lumen (fig 11). In locally advanced cancer, infiltration of the corpus spongiosum and cavernosal bodies can be presented [22].

\section{Foreign body}

The urethra is the main and the most vulnerable organ to be damaged if a foreign body is inserted into the urinary tract. The reasons for foreign body insertion into the urethra vary from curiosity, autoerotic stimulation or medical procedures. The material of the foreign bodies is varied.

In most cases US can be the first step in preoperative examination. It can help to detect the size, depth and distance from the meatus of the object to guide the approach to extraction of the foreign object. In contrast to other urethral pathologies, in these cases the fluid insertion is not mandatory $[23,24]$.

Some forms of foreign bodies are hairs in the urethral lumen. One of the forms of treatment of anterior urethral strictures, in particular in the penile part, is the using of skin flap [25]. The principle is to use the skin with no hairs, but in some cases it is impossible. In this situation hairs growing inside the urethral lumen can be a source of infection or urethral stones. In SUG these structures are visible as linear, hyperechogenic, mobile structures (fig 12) [5].

\section{Periurethral abscess}

A periurethral abscess is a life-threatening infection of the male urethra and periurethral tissue and frequently a sequela of gonococcal infection or urethral stricture disease. Rarest causes are urethral perforation after traumatic catherisation or necrosis in the place of the cuff of artificial urethral sphincter installation. A periurethral abscess arises initially when a Littré gland becomes obstructed by inspissated pus or fibrosis. The most common infecting organisms are gram-negative rods, enterococci, and anaerobes. Pseudodiverticulum formation results 


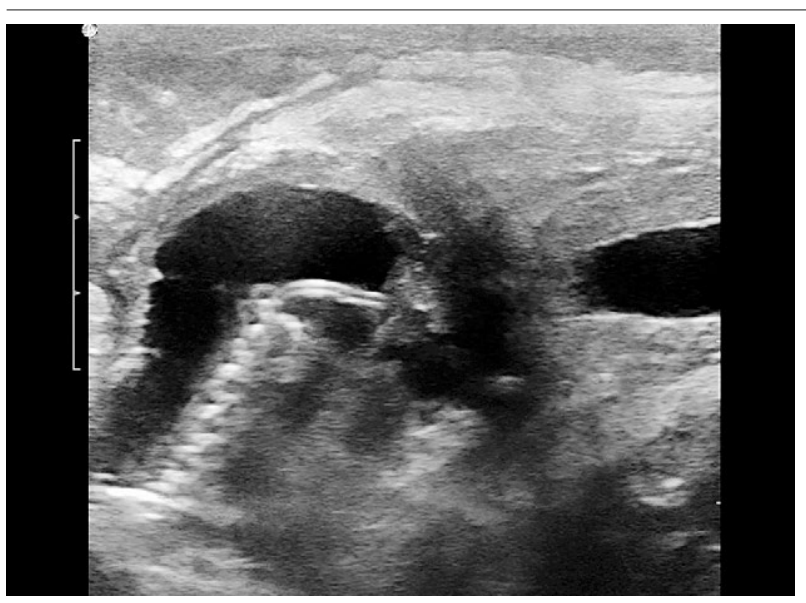

Fig 13. Periurethral abscess. The fluid is surrounding an artificial urethral sphincter's cuff.

from urethral communication with a periurethral abscess. Because the tunica albuginea of the penis prevents the dorsal spread of infection, the abscess tends to track ventrally along the corpus spongiosum, where it is confined by the Buck fascia. However, when the Buck fascia is perforated, there can be extensive necrosis of the subcutaneous tissue and fascia [26].

In sonography, the presentation of the abscess varies from the degree of infection. In an early stage, the picture is similar to urethral diverticulum. In more advanced stages, the fluid is surrounding the corpus spongiosum and penetrates to subcutaneous tissues of the penis, the scrotum or perineum (fig 13).

\section{Conclusion}

SUG is a fast and easy method for performing an examination which allows an assessment of the male anterior urethra. It is mainly used in the diagnosis of urethral strictures but it may be useful in investigating of other patholgies of male urethra. The main limitation of this study is the experience of the examiner. Despite this, SUG can be a "first step" in the evaluation of the male urethra.

After a review of the literature and after some personal practical experience with urethral ultrasound, we believe that this technique can be recommended for the wider use in the diagnosis of any urethral pathology.

\section{Conflict of interest: none}

\section{References}

1. Cunnigham JH. The diagnosis of stricture of the urethra by Roentgen rays. Trans Am Assoc Genitourin Surg 1910;5:369-371.
2. McCallum RW, Colapinto V. The role of urethrography in urethral disease. Part I. Accurate radiological localisation of the membranous urethra and distal sphincter in normal male subjects. J Urol 1979;122:607-611.

3. McAninch JW, Laing FC, Jeffrey RB Jr. Sonourethrography in evaluation of urethral strictures: a preliminary report. J Urol 1988;139:294-297.

4. Berná-Mestre JD, Balmaceda T, Martínez D, et al. Optimisation of sonourethrography: the clamp method. Eur Radiol 2018;28:1961-1968.

5. Krukowski J, Kałużny A, Matuszewski M. Can ultrasonography be useful in the diagnosis of urethral disorders of female-to-male transsexuals? Med Ultrason 2019;21:359361.

6. Krukowski J, Kałużny A, Kłącz J, Matuszewski M. Comparison between cystourethrography and sonourethrography in preoperative diagnostic management of patients with anterior urethral strictures. Med Ultrason 2018;20:436-440.

7. Mitterberger M, Christian G, Pinggera GM, et al. Gray scale and color Doppler sonography with extended field of view technique for the diagnostic evaluation of anterior urethral strictures. J Urol 2007;177:992-996.

8. Talreja SM, Tomar V, Yadav SS, et al. Comparison of sonoelastography with sonourethrography and retrograde urethrography in evaluation of male anterior urethral strictures. Turk J Urol 2016;42:84-91.

9. Gupta N, Dubey D, Mandhani A, Srivastava A, Kapoor R, Kumar A. Urethral stricture assessment: a prospective study evaluating urethral ultrasonography and conventional radiological studies. BJU Int 2006;98:149-153.

10. Chiou RK, Anderson JC, Tran T, Petterson RH, Wobig R, Taylor RJ. Evaluation of urethral strictures and associated Abnormalities using high-resolution and color Doppler ultrasound. Urology 1996;47:102-107.

11. Allen D, Mishra V, Pepper W, Shah S, Motiwala H. A single-center experience of symptomatic male urethral diverticula. Urology 2007;70:650-653.

12. Shalev M, Mistry S, Kernen K, Miles BJ. Squamous cell carcinoma in a female urethral diverticulum. Urology 2002;59:773.

13. Cinman NM, McAninch JW, Glass AS, Zaid UB, Breyer BN. Acquired Male Urethral Diverticula: Presentation, Diagnosis and Management. J Urol 2012;188:1204-1208.

14. Miller J, Hauck EW, Rohde V, Weidner W. Giant ureethral diverticulum - unusual complication following ventral buccal mucosa onlay graft urethroplasty. Urol Int 2006;77:368370.

15. Hatgaongar A. A Comparative Study of Sonourethrography and Retrograde Urethrography in Evaluation of Anterior Male Urethral Strictures. Int J Sci Stud 2014;2:5-12.

16. Friedland GW, Nino-Murcia M, Gill HS, Perkash I. Acquired Nontraumatic Lesions of Urethra. In: Jafri SZH, Amendola MA, Diokno AC (eds). Lower Genitourinary Radiology: Imaging and Intervention. 1st edition, Springer, 1998:352-389.

17. Treviño-Rangel RdJ, Bodden-Mendoza BA, Cantú-Salinas N, García-Rodríguez MA. Decision-making in the manage- 
ment of an incomplete urethral duplication in a young male. Medicina Universitaria 2015;17):94-96.

18. Jafri SZ, Roberts JL, Berger BD. Fistulas of the genitourinary tract. In: Pollack HM, McClennan BL (eds). Clinical urography. 2000:2992-3011.

19. Sun M, Xu W, Guo S, Ma W, Xu H, Sun R. Giant urethral calculus in anterior urethral diverticulum: a case report. BMC Urol 2019;29:71.

20. Kotkar K, Thakkar R, Songra M. Giant urethral calculus. J Surg Case Rep 2011;2011:9.

21. Zhu JA, Hu B, Zhang J, Jin SB, Chen ZD, Wu DL. Ultrasonographic assessment of urethral condyloma acuminatum in men. Zhonghua Yi Xue Za Zhi 2005;85:773-776.

22. Krukowski J, Czajkowski M, Kłącz J, Wawrzaszek O, Gołębiewska M, Matuszewski M. Primary urethral carcino- ma - unexpected cause of urethral stricture. Case report and review of the literature. Med Ultrason 2019;21:494-496.

23. Barzilai M, Cohen I, Stein A. Sonographic detection of a foreign body in the urethra and urinary bladder. Urol Int 2000;64:178-180.

24. Shokoohi H, Kendrick Z, Sikka N, Boniface KS. Sonographic localization of a retained urethral foreign body in an elderly patient. J Clin Ultrasound 2018;46:296298.

25. Orandi A. One stage urethroplasty: 4-year followup. J Urol 1972;107:977-980.

26. Kawashima A, Sandler CM, Wasserman NF, LeRoy AJ, King BF Jr, Goldman SM. Imaging of urethral disease: a pictorial review. Radiographics 2004;24 Suppl 1:S195S216. 